\title{
The association of sociodemographic
} characteristics and sexual risk behaviors with
health literacy toward behaviors for preventing
unintended pregnancy among university students

This article was published in the following Dove Press journal:

Journal of Multidisciplinary Healthcare

\section{Saowanee Thongnopakun \\ Tepanata Pumpaibool \\ Ratana Somrongthong \\ College of Public Health Sciences, \\ Chulalongkorn University, Bangkok, \\ Thailand}

Correspondence: Tepanata Pumpaibool College of Public Health Sciences, Chulalongkorn University, Institute Building 2-3, Soi Chulalongkorn 62, Phyathai Rd., Pathumwan, Bangkok 10330, Thailand

Tel +6622188193

Fax +6622556046

Email tepanata.p@chula.ac.th

\begin{abstract}
Purpose: The aim of this study was to determine whether there is an associated effect between sociodemographic characteristics and sexual risk behaviors with health literacy in preventing unintended pregnancy among university students in Chon Buri province, Thailand.

Participants and methods: A cross-sectional study design was used. The data were collected between February and May, 2017. A self-administered questionnaire was developed by the Ministry of Public Health and supported by the evolving concept of health literacy of Nutbeam. This questionnaire was then applied to collect data from 418 university students. Descriptive statistical and binary logistic regression methods were used for data analysis in this study.

Results: Half the students exhibited inappropriate behaviors to prevent unintended pregnancies. However, half the respondents had been educated to prevent unintended pregnancies. Nearly onethird of the students had experienced sexual intercourse. Binary logistic regression was used to analyze an association between the behavior for unintended-pregnancy prevention with sociodemographic characteristics and the health literacy of university students. The factors assessed were current residence type (the adjusted odds ratio $[\mathrm{aOR}]=1.897,95 \% \mathrm{CI}=1.123-3.205$ ), previous sexual intercourse $(\mathrm{aOR}=3.263,95 \% \mathrm{CI}=1.735-6.139)$, cognitive health to prevent unintended pregnancy $(\mathrm{aOR}=1.095,95 \% \mathrm{CI}=1.019-1.176)$, decision skills in choosing appropriate practices to prevent unintended pregnancy $(\mathrm{aOR}=1.289,95 \% \mathrm{CI}=1.182-1.405)$, and self-management to prevent unintended pregnancy $(\mathrm{aOR}=1.113,95 \% \mathrm{CI}=1.005-1.232)$.

Conclusion: This study indicated that university students who had experienced sexual intercourse and had low health literacy were more likely to exhibit inappropriate behaviors concerning the lack of prevention of unintended pregnancies. The results will provide health professionals with information to develop more effective prevention and intervention programs.
\end{abstract}

Keywords: health literacy, behaviors for preventing unintended pregnancy, adolescent

\section{Introduction}

Youth is the developmental phase in the human lifecycle between childhood and maturity. ${ }^{1}$ Young people undergo various changes in terms of their physical, cognitive, emotional, and sexual development. ${ }^{2}$ These changes become risk factors for premarital sexual behavior, adolescent pregnancy, abortion, and sexually transmitted diseases (STDs), such as acquired immunodeficiency syndrome. ${ }^{3}$

Unintended pregnancies among young people are a worldwide problem in both developed and developing countries. ${ }^{4}$ Unintended pregnancies are often related to 
individual characteristics, knowledge, attitudes, practices, and age at the first occurrence of sexual intercourse. ${ }^{5}$ Misconceptions about sex and the discontinuation of contraception are the main causes of adolescent pregnancy globally. ${ }^{6}$

In 2016, the number of Thai female adolescents aged 15-19 years was $2,262,832$. The birth rate for this age group was 44.8 births per 1,000 youths, ${ }^{7}$ which was higher than the average birth rate for adolescent females in the Asia-Pacific region. ${ }^{8}$ According to the Abortion Surveillance in Thailand Report of 2013, two-thirds of this age group first had sexual intercourse at 17 years of age, and more than half of them did not use contraception ${ }^{9}$ because they forgot, got carried away by emotions, did not have sufficient time, or felt that condoms reduced pleasure for the male. ${ }^{10}$ In 2015, the Ministry of Public Health in Thailand reported that in Chon Buri province, there were 3,286 births. The birth rate among girls aged $15-19$ years was 66.3 cases per 1,000 youths. This number was the highest in Thailand. ${ }^{11}$

Health literacy is important in terms of promoting healthy preventive behavior. ${ }^{12}$ The World Health Organization has defined health literacy as "the development of the cognitive and social skills which determine the motivation and ability of individuals to gain access to, understand and use information in ways which promote and maintain good health". ${ }^{13}$ Data from many developed countries show that people who had low health literacy levels also had low accessibility to health information and low utilization of health services. ${ }^{14}$ Low health literacy has been linked to poor socioeconomic circumstances, and such circumstances, in turn, have been associated with adverse effects on health. ${ }^{15}$ Despite these findings, there has been little research on university students concerning their health literacy and its relationship to behaviors that prevent pregnancy. Therefore, this study aimed to determine the association of sociodemographic characteristics and sexual risk behaviors with health literacy toward behaviors for preventing unintended pregnancy among university students in Chon Buri province, Thailand. The results will serve as a basis for developing programs to prevent unintended pregnancies among university students.

\section{Participants and methods Study design}

This was an analytical cross-sectional study. It was designed to associate the effects of sociodemographic characteristics and sexual risk behaviors with health literacy on preventing unintended pregnancy among university students in Chon Buri province, Thailand.

\section{Population sample and sampling technique}

A cross-sectional study was conducted at one of the four government universities in Thailand. The university is situated in an area known for industry and tourism in the eastern part of the country. The sample size was calculated using Krejcie and Morgan's ${ }^{16}$ formula at a CI of $95 \%$. The sample size was 380 university students. An estimated $10 \%$ of the missing data was added; thus, 418 university students from 16 departments were recruited. As the consequences of unintended pregnancy have more effect on female, the participants of the study were Thai female university students in their first to fourth year of undergraduate studies. All participants volunteered to be in the study, and none had a history of pregnancy. The sampling process used the multistage technique, consisting of the three following stages: 1) the United Nations Educational, Scientific and Cultural Organization criteria ${ }^{17}$ were employed to proportionally stratify the 16 departments into eight groups: a) the Humanities and Social Science group, b) the Health Science group, c) the Business Administration group, d) the Education group, e) the Fine and applied arts group, f) the Engineering group, g) the Science and Technology group, and h) the Physical Science group; 2) the classrooms of the selected faculty members were randomized; and 3) all students in the classrooms were recruited. If the number of students exceeded the study's parameters, students would draw lots to be excluded from the study. The survey was carried out from February to May, 2017.

\section{Materials and data collection}

The questionnaire was specifically designed as a tool for this study, except the health literacy portion, which was adapted from the health literacy scale for unwanted-pregnancy prevention among Thai female adolescents created by the Ministry of Public Health ${ }^{18}$ and supported by the evolving concept of health literacy of Nutbeam. ${ }^{15}$ The questionnaire was composed of 79 questions divided into four parts, as follows: 1) sociodemographic characteristics (11 questions, such as age, grade point average, parents' marital status, parents' relationship, current residence type, and average income per month); 2) sexual risk behaviors (15 questions, for example, those related to having a boyfriend, hugging and kissing experiences, sexual experiences, and so on); 3) health literacy for pregnancy prevention (35 questions); and 4) behaviors to prevent unintended pregnancy (18 questions). A Likert scale was used for parts 3 and 4 of the questionnaire. Data collection was validated via questionnaire by five experts in 
the area of public health and adolescent sexual behavior. The content validity was tested, and the questionnaire corrected. The items-objective congruence index, which was 0.72 , was used to obtain validity from five experts.

A pilot study was conducted to test the reliability of the questionnaire with a sample of 30 students who had characteristics similar to the respondents. The Cronbach's alpha for the health literacy of unintended-pregnancypreventive behavior was 0.73 , whereas that of behavior to prevent unintended pregnancy was 0.88 ; these results were considered acceptable. The total score for health literacy for pregnancy prevention was 105 points, and the total score for behavior to prevent unintended pregnancy was 72 points. The score from each item was summed up to classify the mean level of health literacy. The total score for health literacy was classified into two categories, namely inappropriate or appropriate. The mean was used when evaluating behavior to prevent unintended pregnancy. As was done for health literacy, the total score of behavior to prevent unintended pregnancy was classified into two levels, namely inappropriate and appropriate.

\section{Data analysis}

The data collection took place from February to May, 2017. Data analysis was carried out using SPSS version 22 (university licensed). Descriptive statistics were used to describe sociodemographic characteristics, sexual risk behaviors, health literacy for pregnancy prevention, and behavior to prevent unintended pregnancy. The data were quantified as the frequency, percentage, mean, minimum, maximum, and SD. Binary logistic regression analysis was employed to evaluate independent variables associated with behaviors for preventing unintended pregnancy, which was a dichotomous variable in this study; inappropriate behavior to prevent unintended pregnancy was coded as 1 , and appropriate behavior was coded as 0 . A $p$-value $\leq 0.05$ was considered to represent statistical significance.

\section{Ethical considerations}

Ethical approval was obtained from the Ethics Review Committee for Human Research Subjects, Burapha University (certified code: Hu 029-2560). Before participating in the study, the study objectives and data-collection procedures were fully explained to the university students, who then signed a written informed consent form to indicate their willingness to participate in the study. The code name was used to protect the subject's privacy, and the data were kept confidential.

\section{Results}

In total, 418 university students aged 18-24 years were enrolled in the study. Three-quarters of the respondents had grade point averages higher than 2.5. One-quarter of the respondents reported that their parents were separated. In addition, one-quarter lived in the university dormitory. Their average income was 2,000-30,000 baht per month. Nearly three-fifths did not have a boyfriend. Furthermore, half of the respondents had hugging and kissing experience, while nearly one-third had experienced sexual intercourse, and all of them used contraception, as shown in Table 1. Half of the respondents had appropriate health literacy to prevent unintended pregnancy, as shown in Table 2. Finally, only half engaged in appropriate behaviors for preventing unintended pregnancy, as shown in Table 3.

Analysis using the chi-square test revealed that the current residence type ( $p=0.002)$, having a boyfriend ( $p=0.015)$, hugging and kissing experience $(p=0.003)$, previous sexual

Table I Participants' sociodemographic characteristics

\begin{tabular}{lll}
\hline Sociodemographic characteristics & $\begin{array}{l}\text { Number } \\
(\mathbf{n = 4 1 8})\end{array}$ & Percentage \\
\hline $\begin{array}{l}\text { Age (years) } \\
\bar{x}=20.0, \text { SD=I.3, Min=18, Max=24 }\end{array}$ & \\
Grade average point & & \\
$\quad<2.5$ & 117 & 28.0 \\
$\geq 2.5$ & 301 & 72.0 \\
Parent marital status & & \\
$\quad$ Separated & 108 & 25.8 \\
$\quad$ Married & 310 & 74.2 \\
Current residence type & & \\
$\quad$ Dormitory outside the university & 312 & 74.6 \\
$\quad$ Dormitory in the university & 106 & 25.4 \\
Average income per month (baht) & & \\
$\bar{x}=7348.80$, SD=3482.70, Min=2000.00, Max=30000.00 & \\
Have had a boyfriend & & \\
$\quad$ Yes & 175 & 41.9 \\
No & 243 & 58.1 \\
Hugging and kissing experience & & \\
Yes & 232 & 55.5 \\
No & 186 & 44.5 \\
Previous sexual intercourse (vaginal) & & \\
Yes & 129 & 30.9 \\
No & 289 & 69.1 \\
\hline
\end{tabular}

Table 2 Participants' health literacy to prevent unintended pregnancy

\begin{tabular}{|c|c|c|}
\hline $\begin{array}{l}\text { Health literacy to prevent } \\
\text { unintended pregnancy }\end{array}$ & $\begin{array}{l}\text { Number } \\
(n=418)\end{array}$ & Percentage \\
\hline Inappropriate (score $<76$ ) & 202 & 48.3 \\
\hline Appropriate (score $\geq 76$ ) & 216 & 51.7 \\
\hline $\bar{x}=75.77, \mathrm{SD}=10.02, \mathrm{Min}=38, \mathrm{Max}=100$ & & \\
\hline
\end{tabular}


Table 3 Participants' behavior to prevent unintended pregnancy

\begin{tabular}{|c|c|c|}
\hline $\begin{array}{l}\text { Behavior to prevent } \\
\text { unintended pregnancy }\end{array}$ & $\begin{array}{l}\text { Number } \\
(n=4 \mid 8)\end{array}$ & Percentage \\
\hline Inappropriate $($ score $<46)$ & 193 & 46.2 \\
\hline Appropriate (score $\geq 46$ ) & 225 & 53.8 \\
\hline \multicolumn{3}{|c|}{$\bar{x}=46.59, \mathrm{SD}=7.708, \mathrm{Min}=26, \mathrm{Max}=68$} \\
\hline
\end{tabular}

intercourse $(p<0.001)$, cognitive health to prevent unintended pregnancy $(p=0.001)$, decision-making skills in choosing appropriate practices to prevent unintended pregnancy $(p<0.001)$, self-management to prevent unintended pregnancy $(p<0.001)$, and media and information literacy to prevent unintended pregnancy $(p=0.008)$ were significantly associated with unintended-pregnancy-preventive behaviors among university students ( $p$ value $\leq 0.05)$. The results are shown in Table 4 .

Table 4 Associations between sociodemographic characteristics and health literacy toward behavior to prevent unintended pregnancy among university students (chi-square tests)

\begin{tabular}{|c|c|c|c|c|c|}
\hline \multirow[t]{2}{*}{ Factors } & \multirow[t]{2}{*}{ n (\%) } & \multicolumn{2}{|c|}{$\begin{array}{l}\text { Behavior to prevent } \\
\text { unintended pregnancy }\end{array}$} & \multirow[t]{2}{*}{$\chi^{2}$} & \multirow[t]{2}{*}{$p$-value } \\
\hline & & $\begin{array}{l}\text { Appropriate } \\
(n=225,53.8 \%)\end{array}$ & $\begin{array}{l}\text { Inappropriate } \\
(n=\mid 93,46.2 \%)\end{array}$ & & \\
\hline Age (years) & & & & 1.014 & 0.314 \\
\hline$\leq 20$ & $247(59.1)$ & 138 & 109 & & \\
\hline$>20$ & $171(40.9)$ & 87 & 84 & & \\
\hline \multicolumn{6}{|l|}{$\bar{x}=20.0, S D=1.3, \operatorname{Min}=18, \operatorname{Max}=24$} \\
\hline Grade point average & & & & 0.187 & 0.665 \\
\hline$<2.5$ & $117(28.0)$ & 61 & 56 & & \\
\hline$\geq 2.5$ & $301(72.0)$ & 164 & 137 & & \\
\hline Parent marital status & & & & 2.557 & 0.110 \\
\hline Separated & $108(25.8)$ & 51 & 57 & & \\
\hline Married & $310(74.2)$ & 174 & 136 & & \\
\hline Current residence type & & & & 10.035 & 0.002 \\
\hline Dormitory outside the university & $312(74.6)$ & 181 & 129 & & \\
\hline Dormitory in the university or staying with parents & $106(25.4)$ & 44 & 64 & & \\
\hline \multicolumn{6}{|l|}{$\bar{x}=75.778, S D=10.027, M i n=38, M a x=100$} \\
\hline Average income per month (baht) & & & & 2.593 & 0.107 \\
\hline$\leq 5,000$ & $138(33.0)$ & 82 & 56 & & \\
\hline$>5,000$ & $280(67.0)$ & 143 & 137 & & \\
\hline \multicolumn{6}{|l|}{$\bar{x}=7348.8, S D=3482.7, M i n=2000.0, M a x=30000.0$} \\
\hline Having a boyfriend & & & & 5.885 & 0.015 \\
\hline Yes & $175(4 \mid .9)$ & 82 & 93 & & \\
\hline No & $243(58.1)$ & 143 & 100 & & \\
\hline Hugging and kissing experience & & & & 8.630 & 0.003 \\
\hline Yes & $232(55.5)$ & 110 & 122 & & \\
\hline No & $186(44.5)$ & 115 & 71 & & \\
\hline Previous sexual intercourse (vaginal) & & & & 26.942 & $<0.001$ \\
\hline Yes & $129(30.9)$ & 45 & 84 & & \\
\hline No & $289(69.1)$ & 180 & 109 & & \\
\hline \multicolumn{6}{|l|}{ unintended pregnancy } \\
\hline Poor & $272(65.1)$ & 146 & 126 & & \\
\hline Good & $146(34.9)$ & 79 & 67 & & \\
\hline \multicolumn{6}{|l|}{$\bar{x}=9.6, \mathrm{SD}=1.8, \operatorname{Min}=4.0, \operatorname{Max}=15.0$} \\
\hline Cognitive health to prevent unintended pregnancy & & & & 10.177 & 0.001 \\
\hline Poor & $302(72.2)$ & 148 & 154 & & \\
\hline Good & $116(27.8)$ & 77 & 39 & & \\
\hline \multicolumn{6}{|l|}{$\bar{x}=22.2, \mathrm{SD}=3.4, \operatorname{Min}=\mid 1.0, \operatorname{Max}=30.0$} \\
\hline Communication skills in enhancing skills to prevent unintended pregnancy & & & & 1.139 & 0.286 \\
\hline Poor & $308(73.7)$ & 161 & 147 & & \\
\hline Good & $110(26.3)$ & 64 & 46 & & \\
\hline $\bar{x}=9.6, S D=2.6, M i n=2.0, M a x=15.0$ & & & 46 & & \\
\hline
\end{tabular}


Table 4 (Continued)

\begin{tabular}{|c|c|c|c|c|c|}
\hline \multirow[t]{2}{*}{ Factors } & \multirow[t]{2}{*}{ n (\%) } & \multicolumn{2}{|c|}{$\begin{array}{l}\text { Behavior to prevent } \\
\text { unintended pregnancy }\end{array}$} & \multirow[t]{2}{*}{$\chi^{2}$} & \multirow[t]{2}{*}{$p$-value } \\
\hline & & $\begin{array}{l}\text { Appropriate } \\
(n=225,53.8 \%)\end{array}$ & $\begin{array}{l}\text { Inappropriate } \\
(n=193,46.2 \%)\end{array}$ & & \\
\hline $\begin{array}{l}\text { Decision-making skills in choosing appropriate practice to prevent } \\
\text { unintended pregnancy }\end{array}$ & & & & 65.121 & $<0.001$ \\
\hline Poor & $270(64.6)$ & 106 & 164 & & \\
\hline Good & $148(35.4)$ & 119 & 29 & & \\
\hline \multicolumn{6}{|l|}{$\bar{x}=10.1, \mathrm{SD}=2.9, \mathrm{Min}=0, \mathrm{Max}=15$} \\
\hline Self-management to prevent unintended pregnancy & & & & 24.485 & $<0.001$ \\
\hline Poor & $280(67.0)$ & 127 & 153 & & \\
\hline Good & $138(33.0)$ & 98 & 40 & & \\
\hline \multicolumn{6}{|l|}{$\bar{x}=12.1, \mathrm{SD}=2.8, \mathrm{Min}=0, \mathrm{Max}=15$} \\
\hline Media and information literacy to prevent unintended pregnancy & & & & 6.974 & 0.008 \\
\hline Poor & $287(68.7)$ & 142 & 145 & & \\
\hline Good & |3| (31.3) & 83 & 48 & & \\
\hline $\bar{x}=1 \mathrm{I} .8, \mathrm{SD}=2.8, \mathrm{Min}=0.0, \mathrm{Max}=15.0$ & & & & & \\
\hline
\end{tabular}

Table 5 Binary logistic regression analysis of factors associated with sociodemographic characteristics and health literacy toward behavior to prevent unintended pregnancy among university students

\begin{tabular}{|c|c|c|c|c|c|c|}
\hline \multirow[t]{2}{*}{ Factors } & \multirow[t]{2}{*}{$\mathbf{n}$} & \multirow{2}{*}{$\begin{array}{l}\text { Appropriate, } \\
\text { n (\%) }\end{array}$} & \multicolumn{4}{|l|}{ OR } \\
\hline & & & Crude OR & $95 \% \mathrm{Cl}$ & Adjusted OR & $95 \% \mathrm{Cl}$ \\
\hline \multicolumn{7}{|l|}{ Current residential type } \\
\hline Dormitory outside the university & 310 & I8I (58.4) & Ref & & Ref & \\
\hline Dormitory in the university or staying with parents & 108 & $44(40.7)$ & $0.490 *$ & $0.3 \mid 4-0.765^{*}$ & $1.897^{*}$ & $1.123-3.205^{*}$ \\
\hline \multicolumn{7}{|l|}{ Previous sexual intercourse (vaginal) } \\
\hline Yes & 129 & $45(34.9)$ & Ref & & Ref & \\
\hline No & 289 & $180(62.3)$ & $3.083^{*}$ & $1.999-4.754 *$ & $3.263^{*}$ & $1.735-6.139 *$ \\
\hline Cognitive health to prevent unintended pregnancy & 418 & $225(53.8)$ & $1.142 *$ & $1.076-1.211^{*}$ & $1.095^{*}$ & $1.019-1.176^{*}$ \\
\hline $\begin{array}{l}\text { Decision-making skills in choosing appropriate practice } \\
\text { to prevent unintended pregnancy }\end{array}$ & 418 & $225(53.8)$ & $1.363^{*}$ & I.257-I.479* & $1.289 *$ & I.I82-1.405* \\
\hline Self-management to prevent unintended pregnancy & 418 & $225(53.8)$ & $1.220 *$ & $1.131-1.316 *$ & $1.113^{*}$ & $1.005-1.232 *$ \\
\hline
\end{tabular}

Note: ${ }^{*} p<0.05$.

Abbreviations: OR, odds ratio; Ref, reference group.

Binary logistic regression was used to analyze the factors associated with sociodemographic characteristics and health-literacy-promoting behavior to prevent unintended pregnancy among university students, as follows: current residence type (adjusted odds ratio $[\mathrm{aOR}]=1.897,95 \%$ $\mathrm{CI}=1.123-3.205)$, previous sexual intercourse $(\mathrm{aOR}=3.263$, 95\% CI=1.735-6.139), cognitive health to prevent unintended pregnancy $(\mathrm{aOR}=1.095,95 \% \mathrm{CI}=1.019-1.176)$, decisionmaking skills in choosing appropriate practice to prevent unintended pregnancy ( $\mathrm{aOR}=1.289,95 \% \mathrm{CI}=1.182-1.405)$, and self-management to prevent unintended pregnancy $(\mathrm{aOR}=1.113,95 \% \mathrm{CI}=1.005-1.232)$ at a $p$ value $\leq 0.05$. The results are shown in Table 5.

\section{Discussion}

Health literacy is an important factor in preventing unintended pregnancy among university students. The aim of this study was to explore the association between sociodemographic characteristics and health literacy toward behaviors to prevent unintended pregnancy in this population.

The study showed that half of the university students exhibited an inappropriate level of unintended-pregnancyprevention behaviors. Likewise, a study of the knowledge, attitudes, and intention to prevent unintended pregnancy among female undergraduate students in Bangkok, Thailand, revealed that four-fifths of female university students had poor or moderate intentions to prevent unintended pregnancy. ${ }^{19}$ Similarly, the United Nations Fund for Population Activities (UNFPA, 2013) found that more than half of the adolescents did not engage in pregnancy prevention. ${ }^{8}$ This study presented the following behavioral factors that put adolescents at risk for unintended pregnancy: threequarters of the respondents had dated their boyfriends at an out-of-sight location; three-quarters had been shown 
books/magazines/cartoons/videos containing explicit sexual content by their boyfriends; and nearly three-quarters lived with their boyfriends. The study found that female university students had sexual intercourse because they saw it as proof of love. Pressure from boyfriends often resulted in female university students having little to say about the decision to use contraceptives. ${ }^{20}$ These factors can lead to unintended pregnancy among adolescents, who are influenced by complicated health determinants, such as education and social and financial status. Furthermore, in this study, the binary logistic regression analysis revealed that current residential type, previous sexual intercourse, cognitive health to prevent unintended pregnancy, decision-making skills in choosing appropriate practices for preventing unintended pregnancy, and self-management to prevent unintended pregnancy were significantly associated with behaviors concerning preventing unintended pregnancy.

University students living in university dormitories were 1.897 times more likely to exhibit appropriate behaviors in terms of unintended-pregnancy prevention than university students living outside the university dormitories. However, nearly three-quarters of the university students lived outside the dormitories. This can be explained in that changes in social conditions have allowed university students to have a freer lifestyle. ${ }^{21}$ Likewise, three-quarters of the university students lived outside the university dormitories; such students are at a higher risk for having sexual intercourse, unintended pregnancies, abortions, STDs (including human immunodeficiency virus [HIV]), infections, suicide (if there is no solution to the mentioned problems), and so on. ${ }^{22}$ In addition, many students are forced to live far away from their homes when they are pursuing higher education. Universities have limited dormitory space, so some university students must rent such residences as apartments, condominiums, and houses. Most of these university students live with members of the opposite sex. In such conditions, parents or guardians cannot monitor or control the students' behaviors. $^{23}$

The participants in this study who had not had sexual intercourse were 3.26 times more likely to exhibit appropriate behavior in terms of unintended-pregnancy prevention than university students who had experienced sexual intercourse. The findings of the study showed that one-third of the respondents were sexually active, which is similar to the rate among American teenagers. ${ }^{24}$ However, the percentage of American teenagers who do not use condoms was found to be higher than the rate in this study. ${ }^{24}$ Lack of condom use poses a risk for pregnancy and for contracting STDs, including HIV. ${ }^{10,24}$
The university students who had sexual intercourse used at least one method of contraception. However, only one-quarter used modern contraceptive methods (condoms, contraceptive pills, emergency contraceptive pills, and injectable contraceptives), whereas nearly one-tenth used traditional contraceptive methods (coitus interruptus/external ejaculation method), and one-quarter used both. Condoms remained the contraceptive of choice of university students, as they are among young people in the UK. ${ }^{25}$ Condoms not only prevent pregnancy, but also STDs and HIV. ${ }^{26}$ Another study showed lower condom use than did this study, indicating that self-awareness of preventing STDs among teenagers who had sexual experiences was relatively low because they only occasionally used condoms. It can be assumed that the problem is caused by a lack of knowledge, socialization (in relation to sex education), and pregnancy-prevention guidance from the family. ${ }^{27}$

When the scores for cognitive health to prevent unintended pregnancy increase one point, university students are 1.095 times more likely to exhibit the appropriate unintendedpregnancy-prevention behaviors. This study revealed that most university students had a low level of cognitive health in terms of preventing unintended pregnancy. Many studies have revealed that knowledge about pregnancy is positively correlated to pregnancy-prevention behaviors among teenagers, ${ }^{28,29}$ but this knowledge was low in the present study. In contrast, a European study found no significant relationship between pregnancy, knowledge of the timing of emergency contraception, and knowledge about how to access contraception and sexual health services. ${ }^{30}$ The university students in this study exhibited inappropriate cognitive health to prevent unintended pregnancies, as follows: two-fifths had the misconception that the coitus interruptus/external ejaculation method is the most efficient method of preventing pregnancy, and nearly one-third perceived the use of a "safe period" (7 days before and after menstruation) as the most efficient method of preventing pregnancy, while only one-tenth of the students knew that they could purchase contraceptive pills from a convenience store.

When the scores for decision-making skills increase one point, university students are 1.289 times more likely to exhibit the appropriate unintended pregnancy-prevention behaviors. In this study, three-fifths of the respondents had low levels of this skill in this domain. For instance, three-fifths allowed friends of the opposite sex to hug and kiss them, as they considered it a friendly act. Moreover, nearly half reported that they would accept an offer from boyfriends/ lovers to have sexual intercourse. Decision-making skills are 
accumulated from the university students' reasoning in choosing practices for preventing pregnancy. ${ }^{28}$ There are many methods involving improvements in decision-making skills among adolescents. One study showed that low health literacy and numeracy may play an important role in making decisions regarding the use of contraceptives, which may result in poor health outcomes. ${ }^{11,15}$ Teenagers want parents and other adults to be involved in helping them to understand sexuality and make decisions about sexual behaviors. ${ }^{31}$ Maternal communication has rich potential as an intervention to positively affect the sexual decision making and contraception use of adolescents. ${ }^{32}$ A study of South-African women found that the relationship between discussing condom use with partners and the actual use of condoms indicated the importance of male-partner involvement in women's contraceptive decisions. ${ }^{33}$ When teenagers acquire suitable decision-making skills, they are able to analyze the benefits and drawbacks of declining invitations and avoiding risky behaviors; they will be able to choose how to react and circumvent the negative effects of sexual intercourse, such as STDs, unintended pregnancies, and abortion. ${ }^{33}$

When the self-management scores to prevent unintended pregnancy increase one point, university students are 1.113 times more likely to exhibit the appropriate unintendedpregnancy-prevention behaviors. However, in this study, the university students exhibited inappropriate self-management to prevent unintended pregnancy. In the results, half of the university students adjusted their environment to alleviate their sex drives, which correlates to one study in which half of the participants had reviewed their self-practice and goals and anticipated that their behaviors would serve to prevent pregnancy. However, the Thai female adolescents did not have negotiating self-efficacy with their male counterparts in terms of condom use. Low self-efficacy, insufficient knowledge, and low health literacy levels regarding safe sex affect Thai female adolescents' unintended-pregnancy-prevention behaviors. Therefore, they are unable to negotiate with their partners with regard to condom use. ${ }^{9}$

\section{Conclusion}

The purpose of this study was to investigate the association between sociodemographic characteristics and health literacy resulting in contraceptive use among university students in Chon Buri province, Thailand. Half of the university students exhibited appropriate behaviors with respect to unintendedpregnancy prevention. Health literacy is the main behavioral factor when it comes to preventing unintended pregnancy. University students who had low health literacy were more likely to engage in inappropriate behavior related to preventing pregnancy. The results of this study can provide health professionals with information to develop more effective prevention and intervention programs. This can be accomplished by cooperating with all involved parties, especially in the government sector, to set regulations for a clearer category of outside dormitories, by providing a choice in preventing risky sexual behaviors, by promoting condom use for those living in dormitories outside the university, and by advocating and promoting cognitive health, decision-making skills, and self-management to prevent unintended pregnancies.

\section{Limitations and recommendations}

The context of this study needs to be examined in order to assess the results because the area studied is one of industrialism and tourism. Good cognitive health, decision-making skills, and self-management to prevent unintended pregnancies are imperative for integration. Therefore, future research needs to test the effectiveness of the program. This study suggests that living in an inside or outside dormitory affects the prevention of unintended pregnancies. However, qualitative research is essential to comprehend this occurrence.

\section{Acknowledgments}

The authors wish to thank Chulalongkorn University for the 90th Anniversary Chulalongkorn University Fund for Doctoral Scholarship and the faculty of Public Health at Burapha University for funding this study. The researcher would like to express gratitude to all informants and to the university, which allowed the research to be conducted.

\section{Disclosure}

The authors report no conflicts of interest in this work.

\section{References}

1. Assembly S-FWH. Resolution WHA 64.28: Youth and health risks 2011. Available from: http://apps.who.int/gb/ebwha/pdf_files/WHA64/ A64_R28-en.pdf. Accessed December 3, 2016.

2. Sawyer SM, Afifi RA, Bearinger LH, et al. Adolescence: a foundation for future health. Lancet. 2012;379(9826):1630-1640.

3. Stanger-Hall KF, Hall DW. Abstinence-only education and teen pregnancy rates: why we need comprehensive sex education in the U.S PLoS One. 2011;6(10):e24658.

4. Chandra-Mouli V, Camacho AV, Michaud PA. WHO guidelines on preventing early pregnancy and poor reproductive outcomes among adolescents in developing countries. JAdolesc Health. 2013;52(5):517-522.

5. Richter S, T Mlambo G. Perceptions of rural teenagers on teenage pregnancy. Health SA Gesondheid. 2005;10(2):61-69.

6. Ziyane I, Ehlers V. Swazi youths' attitudes and perceptions concerning adolescent pregnancies and contraception. Health SA Gesondheid. 2006;11(1):31-42.

7. Health BoRHMoP. Situation of reproductive health in adolescent and youth 2016. Available from: http://rh.anamai.moph.go.th/ewt_news. php?nid=23\&filename=index. Accessed January 8, 2017. 
8. Williamson NE. Motherhood in Childhood: Facing the Challenge of Adolescent Pregnancy. New York: United Nations Population Fund; 2013.

9. Tantivess S, Pilasant S, Yamabhai I. Situation Analysis of Adolescent Pregnancy in Thailand 2013. Nonthaburi: Ministry of Public Health; 2013.

10. UNICEF. Situation analysis of adolescent pregnancy in Thailand: Synthesis report 2015. Available from: https://www.unicef.org/thailand/160614_SAAP_in_Thailand_report_EN.pdf. Accessed January $17,2017$.

11. Bureau of Reproductive Health Ministry of Public Health. Teenage and reproductive health 2015. Available from http://rh.anamai.moph.go.th/ ewt_news.php?nid=23\&filename=index. Accessed January 12, 2017.

12. Nutbeam D. Health literacy as a public health goal: a challenge for contemporary health education and communication strategies into the 21st century. Health Promot Int. 2000;15(3):259-267.

13. Smith BJ, Tang KC, Nutbeam D. WHO health promotion glossary: new terms. Health Promot Int. 2006;21(4):340-345.

14. DeWalt DA, Berkman ND, Sheridan S, Lohr KN, Pignone MP. Literacy and health outcomes; a systematic review of the literature. J Gen Intern Med. 2004;19(12):1228-1239.

15. Nutbeam D. The evolving concept of health literacy. Soc Sci Med. 2008;67(12):2072-2078.

16. Krejcie RV, Morgan DW. Determining sample size for research activities. Educ Psychol Meas. 1970;30(3):607-610.

17. Statistics UIf. International Standard Classification of Education: ISCED 2011. Montreal, Quebec: UIS; 2012.

18. Health MoP. Health Literacy Scale for Unwanted Pregnancy Prevention of Thai Female Adolescents. Nonthaburi: 2014.

19. Sirirat C, Pumpaibool T, Phupong V. Knowledge attitude and intention of preventing unwanted pregnancy among female undergraduate students in Bangkok, Thailand. J Health Res. 2015;29 (Suppl 2): S193-S199.

20. De Villiers F, Kekesi K. Social interaction of teenage mothers during and after their pregnancy. South Afr Fam Pract. 2004;46(2):21-24.
21. Patcharasit Suwan. Risk Factors Leading to Unwanted Teenager Pregnancy in the Muang District Chiang Mai Province. Chiang Mai, Thailand: Chiang Mai University; 2006.

22. Wong-arsa W, Kongnguen P, Vuthiarpa S. Factors affecting sexual risk behaviors among adolescents: a Case Study Conducted in One University. J Public Health. 2015;45(3):285-297.

23. Thato S. Premarital sexual behavior among thai adolescents. J Nurs Health Sci. 2007;1(2):3.

24. Kann L, McManus T, Harris WA, et al. Youth risk behavior surveillanceUnited States, 2015. MMWR. Surveill Summ. 2016;65(6):1-174.

25. Tripp J, Viner R. ABC of adolescence: sexual health, contraception, and teenage pregnancy. BMJ. 2005;330(7491):590-593.

26. UNFPA, WHO, UNAIDS. Position statement on condoms and the prevention of HIV, other sexually transmitted infections and unintended pregnancy, 2015. 2016.

27. Siriwan Tumphan. Sexual behaviors and factors correlated with the intention of protection. Nurs J Ministry of Public Health. 2015;25(1):97-109.

28. Wang RH, Wang HH, Hsu MT. Factors associated with adolescent pregnancy-a sample of Taiwanese female adolescents. Public Health Nurs. 2003;20(1):33-41.

29. Frost JJ, Lindberg LD, Finer LB. Young adults' contraceptive knowledge, norms and attitudes: associations with risk of unintended pregnancy. Perspect Sex Reprod Health. 2012;44(2):107-116.

30. Imamura M, Tucker J, Hannaford P, et al; REPROSTAT 2 Group. Factors associated with teenage pregnancy in the European Union countries: a systematic review. Eur J Public Health. 2007;17(6):630-636.

31. Aquilino ML, Bragadottir H. Adolescent pregnancy: teen perspectives on prevention. MCN Am J Matern Child Nurs. 2000;25(4):192-197.

32. Commendador KA. Parental influences on adolescent decision making and contraceptive use. Pediatr Nurs. 2010;36(3):147-156.

33. MacPhail C, Pettifor AE, Pascoe S, Rees HV. Contraception use and pregnancy among 15-24 year old South African women: a nationally representative cross-sectional survey. BMC Med. 2007;5(1):31.
Journal of Multidisciplinary Healthcare

\section{Publish your work in this journal}

The Journal of Multidisciplinary Healthcare is an international, peerreviewed open-access journal that aims to represent and publish research in healthcare areas delivered by practitioners of different disciplines. This includes studies and reviews conducted by multidisciplinary teams as well as research which evaluates the results or conduct of such teams or health

\section{Dovepress}

care processes in general. The journal covers a very wide range of areas and welcomes submissions from practitioners at all levels, from all over the world The manuscript management system is completely online and includes a very quick and fair peer-review system. Visit http://www.dovepress.com/ testimonials.php to read real quotes from published authors. 